\title{
Creating a system of professional learning that meets teachers' needs
}

By William R. Penuel, Philip Bell, and Tiffany Neill

[[intro]]A teacher survey helps science educators set a direction for statewide professional learning.[[/intro]]

Across the country, the field of science education currently faces a dilemma: To support teacher learning in this subject area, how should state- and district-level administrators allocate their scarce dollars? For more than 15 years, the federal government's Math-Science Partnership program had provided a reliable stream of funding for professional development. In 2018, however, that program was eliminated. In effect, this means that local leaders in math and science education can no longer count on steady support from year to year. Now they have to compete with other important subjects for a share of federal resources.

For science teachers, this funding change comes at a particularly inopportune time. Most states have only just adopted ambitious new standards aligned to the Framework for K-12 Science Education (National Research Council, 2012), and teachers are counting on investments in professional learning to help them align their instruction to these goals.

Standards documents themselves can provide some assistance in deciding where to allocate professional learning resources. For example, Learning Forward's Standards for Professional Learning can help leaders evaluate potential learning providers, and the Science Professional Learning Standards developed by the Council of State Science Supervisors (CSSS) describe how professional learning can support specific forms of science learning for all students. But standards are not enough to guide decision making, especially when resources are scarce. 
Through a partnership between CSSS and researchers at both the University of Colorado Boulder and the University of Washington, we have developed a teacher vision survey and process to help state leaders make the most effective investments in science teachers' professional learning. This survey assesses how well teachers' vision for science teaching aligns with that of the new science education framework, particularly when it comes to issues of equity. It also asks teachers to name what support they would most like as they embark on implementing that vision. Thirteen states, including six early adopters of the Next Generation Science Standards, have used data from this survey to establish goals for their states' professional learning systems and select learning resources.

\section{A vision that puts equity at the center}

The Framework for $K$-12 Science Education focuses attention on equity in several important ways. First, it recognizes that all students are born investigators, capable of engaging in science practices from an early age. Also, it emphasizes the need for connecting instruction to students' interests and experiences, particularly when those students come from nondominant communities (e.g., Black students, emerging multilingual students) or have multiple identities that often are marginalized in the sciences (e.g., Latina girls). And finally, the Framework highlights the need to provide all students with time for science and a high-quality curriculum that builds on the practices of their cultural communities (e.g., Indigenous ways of knowing within tribal communities).

The Framework also underscores that learning science is more than memorization of rote facts; it involves actually participating in inquiry-based activities and modeling that enable students to figure out and apply the big ideas of science. According to the framework, all students must have opportunities to develop an understanding of science ideas over time by engaging in science and engineering practices, with the teacher as a partner. 
To make these shifts is no small achievement. To do so, teachers will need to learn about their students' interests, identities, and cultural communities. They will need new ways to elicit students' grasp of science and engineering practice. And they will need to recognize the diverse ways that students draw on their own everyday ways of knowing in their families and communities to make sense of science phenomena.

\section{Determining teachers' vision}

Before state and district leaders can help teachers change their instruction, they will need to ascertain to what degree their vision aligns with that of the Framework. That way, they will know where they need to help teachers reimagine what science teaching should look like and where they simply need to provide teachers with tools for improvement.

Some years ago, Karen Hammerness (2001) developed a straightforward but provocative interview protocol that asked teachers to imagine their ideal classroom and describe what the students are learning and what they and their students are doing in that classroom. We adapted this approach to develop our own vision survey, focusing on five ideas from the framework:

- $\quad$ Science is both knowledge and practice.

- Understanding builds over time.

- Instruction should connect to interest and experience.

- Schools should promote equity.

- $\quad$ Assessment should focus on students' application of core ideas. 
We worked with 40 state-level science education leaders in 13 states to write a set of statements teachers might make about each of these ideas as it relates to their ideal classroom. Some statements aligned with the vision in the framework (e.g., "Students' ideas and questions guide and organize my instruction") and some did not (e.g., "Students are learning science that I think will be useful to them someday in their future"). Both types of statements were ones the state leaders who helped us design the survey had heard teachers voice, so they were strongly grounded in practice. Statements that did not align with the vision were not necessarily incorrect statements, but they could suggest a different set of priorities than the framework emphasizes (e.g., a focus on learning useful facts over applying science ideas).

Our team at the University of Colorado asked 112 elementary teachers and 773 secondary teachers whose names we obtained from a company that maintains lists of K-12 teachers from the 13 ACESSE states to pick those statements that agreed with their vision of an ideal science classroom. What we found was striking, and the pattern was consistent across states: Most teachers' visions centered on the idea of science as both a body of knowledge and practices for developing that knowledge, as well as the need for instruction to connect to students' interests and experiences (see Table 1). Teachers were less focused on equity, and they were almost as likely to endorse statements that were not aligned with this priority as ones that were.

\section{[[Insert Table 1]]}

\section{Eliciting teachers' desires for growth}

In addition to asking about their visions for science education, we presented 10 statements that state leaders had determined were potential priorities for teacher learning and asked teachers to indicate the one area where they'd like to grow the most. The most popular area by far connecting to students' interests and experiences — was already a focus of many teacher visions 
(Table 2). In addition, a sizeable number wanted to learn how to give students more agency in the classroom, leading investigations and driving instruction forward through their questions.

Because we wanted to give state leaders a sense of what contexts for teacher learning might be most effective, we also asked teachers where they found the greatest support for their own professional growth. For the teachers in our sample, district-level professional learning communities, formal professional development opportunities, and standards themselves were important. Teachers also cited their own preservice educational experiences as key supports.

\section{Using the data to develop aims and strategies}

Our research team gave the leaders in our 13 states a report showing the main patterns revealed by their data, and we gave time at a meeting to help them use the data to construct state-specific aim statements for their state's teacher professional learning. Because so few teachers identified equity as a priority in their ideal classroom, many state teams chose to write aim statements that foregrounded equity. And because so many teachers expressed a desire to learn more about how to connect instruction to students' interests and experiences, some state teams made that a focus in their aim statements. Still others blended the two, focusing on the idea that connecting instruction more deeply to students' interests, experiences, and identity could be a central part of an equity strategy — an idea central in the Framework for K-12 Science Instruction. All of the aim statements included measurable, specific goals with a time frame for accomplishing them and the actors responsible for supporting them.

The next step was an effort to co-design with state leaders a set of resources to support states in this work. These resources focused on topics related to eliciting students' interests and experiences, assessing knowledge and practice together, and helping teachers make sense of student ideas in ways that reflect students' varied approaches to knowing and being in the world. Each of these 
topics were chosen because they related to shifts in teaching emphasis related to the Framework. The co-design approach was key in leveraging the expertise of the group and tailoring the tools to the identified aims. One such tool, for example, focused on identifying the different ways students make sense of science, and helping teachers learn how to use students' ideas in instruction.

The resources are freely available on the STEMTeachingTools.org site, and we are studying how state teams are using and adapting them. Already, surveys of state leaders have shown us strong evidence of widespread use: Across 37 different professional development activities, the tools have been used to reach some 8,000 educators in the 13 states. Many more leaders in other states are using the tools to engage educators in sustained professional learning. Overall, these tools were accessed more than 35,000 times within the first two years of their publication.

\section{What can district and state leaders learn from our experience?}

Leaders in all subject areas face challenges in identifying where to allocate resources for professional learning. Allocations based on teachers' own goals for learning may lead teachers to feel a greater sense of investment and agency in directing their own learning. On the other hand, allocations based on gaps between current teacher visions and a target vision embraced by leaders may result in better alignment with the target vision across the state. And, when possible, allocations based on the intersection of teachers' expressed goals and state leaders' target vision may accomplish both of these aims and lead to most effective use of professional learning dollars.

Taking stock of teachers' vision is important, because ultimately the long-term success of any reform depends on teacher buy-in. Educators may comply in the short term with mandates and reforms that are handed down from them, but real change demands sustained professional learning that teachers want to engage in. At the same time, if state leaders deem a particular goal — such as equity - as important, then we need a way to measure progress toward that goal and discuss 
together how to improve. This can involve learning how well teachers' goals align with the state vision and invest in professional learning that will promote greater alignment.

To learn from the kind of survey we gave to teachers, education leaders must have processes for making sense of and determing how to use the data. As data-informed decision-making initiatives always should, ours relied on structured opportunities for looking at and responding to data to help state leaders collectively decide on appropriate professional learning goals for their states. And in a less typical move, we co-developed professional learning resources specifically targeted to those goals and provided data on how teachers used these resources. Because district and state leaders rely so heavily on data to allocate scarce dollars for professional learning, states were excited to have such data available. As such, our project illustrates an approach to making use of a novel kind of data to guide improvement at the systems level.

\section{References}

Hammerness, K. (2001). Teacher's visions: The role of personal ideals in school reform. Journal of Educational Change, 2 (2), 143-163.

National Research Council. (2012). A framework for K-12 science education: Practices, crosscutting concepts, and core ideas. Washington, DC: National Academies Press.

\section{AUTHORID}

William R. Penuel (william.penuel@colorado.edu), University of Colorado Boulder 
Philip Bell, University of Washington

Tiffany Neill, Oklahoma State Department of Education

\begin{abstract}
State-level leaders face a difficult challenge of determining where to invest scarce professional learning dollars. To address this challenge, a team of researchers and state-level science educators surveyed teachers to learn more about their vision for science education and what kind of learning opportunities they preferred. The survey enabled the team to determine how well teachers' ideas about science education aligned with the Framework for K-12 Science Education. They then set state-level aims for professional learning that took into account teacher preferences and any gaps between teacher visions and the vision of science education in the framework. Together, the researchers and state leaders created free learning resources that could help teachers achieve these aims.
\end{abstract}

KEYWORDS

education

science

teacher

professional learning 
professional development

Framework for K-12 Science Education

survey

\section{PULLQUOTES}

Table 1. Teachers' agreement with statements aligned to the Framework for K-12 Science Education

Statement categories $\quad$ Aligned statements chosen Not aligned statements chosen

Science is both knowledge and $\quad M=4.12$

$\mathrm{M}=2.05$

practice
$\mathrm{SD}=1.37$
$\mathrm{SD}=1.19$

Instruction should connect to $\quad \mathrm{M}=4.27$

$M=2.38$

students' interests and
$\mathrm{SD}=1.28$
$\mathrm{SD}=1.24$

experiences

$M=1.22$

$\mathrm{SD}=1.31$

$\mathrm{SD}=0.97$ 


$\begin{array}{lcc}\text { Understanding develops over } & \mathrm{M}=3.16 & \mathrm{M}=1.96 \\ \text { time } & \mathrm{SD}=1.42 & \mathrm{SD}=1.09 \\ & & \mathrm{M}=1.59 \\ \text { Assessment should focus on } & \mathrm{M}=3.23 & \\ \text { students' application of core } & \mathrm{SD}=1.20 & \mathrm{SD}=1.16 \\ \text { ideas } & & \end{array}$

Note: Respondents were asked to select which statements, falling under each of these categories, matched their vision of ideal science instruction. $\mathrm{M}=-$ mean; $\mathrm{SD}=$ standard deviation. 
Table 2. Teacher selections of their desired focus for professional learning

Teachers selecting

Potential learning focus

Percentage Number

Providing students with opportunities to connect the science they learn

in the classroom to what they experience outside of the classroom

$44 \%$

412

Letting students lead investigations even if I don't know how it will end $14 \%$

129

Using student ideas and questions to guide and organize instruction $\quad 10 \%$

94

Focusing science instruction on ideas in depth, even if that means

covering fewer topics

$9 \%$

87

Asking students to construct an explanation of a phenomenon before I

think they can construct a complete explanation so I can decide what I $\quad 7 \%$

61

need to teach next

Integrating local (immediate) cultures to make meaningful connections

in science learning

$6 \%$

56

Emphasizing the relationship between content across grade levels by

asking students to make connections themselves

$4 \%$ 
Planning instruction that builds on what my students already know and can do

Making sure my assessments align to what students had the chance to

$2 \%$

20

learn

Trying to name the things students do as science and engineering

$1 \%$

11

practices when what students do resemble practices 